\title{
The Role of Switching Costs in O2O Platforms: Antecedents and Consequences
}

\author{
${ }^{1}$ Minghui Kang, ${ }^{2}$ Yiwen Gao, ${ }^{3}$ Tao Wang* and ${ }^{4}$ Meng Wang \\ School of Economics Management \\ Southwest Jiaotong University \\ ${ }^{1}$ kmhui66@126.com,2419360294@qq.com, ${ }^{3}$ ccnuwt@swufe.edu.cn, \\ 4398580368@qq.com
}

\begin{abstract}
Online to offline is a new business mode combining the online shopping and the front line transactions. No previous studies have simultaneously examined these variables as antecedents of e-loyalty intention or the possible relationships among them within $\mathrm{O} 2 \mathrm{O}$ platform. Our paper has examined the effects of inertia; perceived ease of use, customization and quality of offering on the consumer's switching costs. These findings provide a theoretical foundation for academics and also practical guidelines for service providers in dealing with the promotion of loyalty at $\mathrm{O} 2 \mathrm{O}$ platforms.
\end{abstract}

Keywords: O2O platform, switching cost, e-loyalty, inertia

\section{Introduction}

The recent emergence of the mobile revolution led by smartphones has presented a new paradigm for transaction mode. Online to Offline, which is also called $\mathrm{O} 2 \mathrm{O}$, is a new business mode combining the online shopping and the front line transactions. The concept of $\mathrm{O} 2 \mathrm{O}$ was firstly proposed by Alex Rampell, the co-founder and CEO of TrialPay, in November, 2011 [1]. More precisely, $\mathrm{O} 2 \mathrm{O}$ is the business model behind recent successful startups such as taxihailing apps and Living Social [2]. Business owners apply the business model to gain customers both online and offline.

From the integrated environment, the development potential of $\mathrm{O} 2 \mathrm{O}$ is huge. In recent years, mobile Internet has developed rapidly in China. Moreover, according to report of iResearch, up to December, 2013, the penetration rate of China Internet has been over 45\%, and the number of cellphone net citizens has reached 500 million. $\mathrm{O} 2 \mathrm{O}$ focuses on life services which correlate with geographical position. The mobile terminal is more suitable for the development of $\mathrm{O} 2 \mathrm{O}$ because of the location property. And the portability of mobile equipment is also fit for user's real-time demand. The era of mobile Internet impels the mobile terminals to become the most important development direction of $\mathrm{O} 2 \mathrm{O}$.

The key of $\mathrm{O} 2 \mathrm{O}$ is to attract users online and direct them to physical stores in the offline realm. It is a combination of payment model and foot traffic generator for merchants (as well

as a "discovery" mechanism for consumers)and also creates offline purchases [1]. With $\mathrm{O} 2 \mathrm{O}$ sites, everything is easily and obviously quantified and tracked since every transaction (or reservation) happens online.

Groupon, the premier example of $\mathrm{O} 2 \mathrm{O}$ Commerce, is unique in that it provides coupons for local services directly to consumers [3]. Consumers sign up to receive special offers from Groupon-narrowing down their interests via the site's functionality-and receive one offer each day in their local area [4]. 
The $\mathrm{O} 2 \mathrm{O}$ concept raised by Alex Rampell, introduced to China in November, 2011, has led to a discussion. The $\mathrm{O} 2 \mathrm{O}$ mode is successfully applied by Panshi Network Ad Member Community, the largest website ad alliance in China.

The group-buying has been the most hyped and successful example of how $\mathrm{O} 2 \mathrm{O}$ works. However, many of yesterday's speakers slammed the group-buying model because many players choose the market due to low entry barriers, compete heavily on price and sell to unloyal price sensitive customers that will switch from merchant to merchant, looking for the best deal, ultimately hurting the merchants [5].

$\mathrm{O} 2 \mathrm{O}$ e-commerce forms the information flow and material flow so that the relationship between online and offline becomes closer. It also broadens e-commerce's development areas and makes e-commerce enter a new stage [6]. However there are lots of problems to be resolved. Many $\mathrm{O} 2 \mathrm{O}$ patterns are immature. Group-buying enterprises, the represents of $\mathrm{O} 2 \mathrm{O}$, have a mass layoff at the middle of 2011 due to immature management. Also platforms of taxi-hailing retain customers through heavy subsidy [7]. However, will customer use this platform sequentially without these subsidies? And what impels the customers to remain and keeps them loyalty to the platforms?

Lots of scholars studied loyalty in the context of e-commerce [8-11]. However, no previous studies have simultaneously examined these variables as antecedents of e-loyalty intention or the possible relationships among them within $\mathrm{O} 2 \mathrm{O}$ platform. For $\mathrm{O} 2 \mathrm{O}$ platform, it is more difficult to develop long-term relationships with customers than with sellers. So we will discuss the customers' switching costs and loyalty to platform in this paper.

The rest of the paper is organized as follows: section 2 provides a review pf the existing literature on switching costs and e-loyalty. Section 3 presents the research hypothesizes, specifying the antecedents determining switching costs and loyalty on $\mathrm{O} 2 \mathrm{O}$ platforms. Section 4 outlines the research methodology. Section 5 provides the results of empirical tests, followed by a summary of the findings and the discussions of the implications. At the end of the paper, limitations and suggestions are identified for future researches.

\section{Theoretical Background}

\subsection{Switching Bost}

Consumers incur one-time costs when switching from one supplier or marketplace to another. These costs are called switching costs (barriers) [12]. Switching cost is a main reason why buyers stay with or switch a seller. Most researchers agree that switching costs reduce switching because they make customers more difficult or costly to change providers [13]. Fornell contended that switching costs included not only economic costs but also search costs, transaction costs, learning costs, loyal customer discounts, customer habit, emotional cost, etc. [14]. Burnham identified three types of switching costs: procedural, financial and relational switching costs [15]. But Klemperer classified switching costs into three categories: learning costs, transaction costs and artificial or contractual costs[16]. Besides, other researchers also conducted this type of studies in other contexts. For example, Kun et al. suggested three types of switching costs in brick-and-click bookstores: search cost, performance loss cost, and uncertainty cost [17].

As the antecedents of switching costs, Burnham identified three components: market characteristics, consumer investments and domain expertise [15]. In prior research, some scholars studied the antecedents of switching costs on the following components: customersupplier relationship characteristics and customer relationship [18]. Using the case of e-book readers, Huang and Hsieh reveal a nomological framework of antecedents to switching costs: relative advantage, compatibility, complexity and domain expertise [19]. 


\subsection{E-loyalty}

There are multiple definitions of loyalty in the literature. The strength of the relationship between an individual's relative attitude and repeat patronage is supposed as loyalty [20]. And Oliver [21] defined customer loyalty as "a deeply held commitment to re-buy or repatronize a preferred product or service consistently in the future, despite situational influences and marketing efforts which have the potential to cause switching behavior".

In the context of e-commerce, loyalty is defined as a customer's favorable attitude toward the e-retailer that leads to repeat buying behavior [8]. The concept of e-loyalty extends the traditional concept of loyalty to online consumer behavior [9].

Building loyalty is seen as a central task for the firm's manager [22]. Creating loyalty depends on better demands meeting than that of competitors [23]. Loyalty is the expected outcome of using direct marketing successfully or of initiating brand-building activities [24]. It is the pivotal factor for firm's survival and development [25]. Managers need to better understand the determinants of customers' attitudes towards this technology and develop strategies that will lead to customer loyalty [10]. And some scholars contend that target customers have partially determined the level of loyalty [26].

Oliver [21] built a four-stage loyalty model: cognitive stage (loyalty to information), affective stage (Loyalty to a liking), conative stage (loyalty to an intention) and action stage (loyalty to action inertia), which defined different dimensions of loyalty. While Carmen and Araceli [18] posed three loyalty-related outcomes of perceived switching costs: (1) affective loyalty (a positive and willing attitude); (2) cognitive loyalty (awareness of, or preference for, the products/services of a particular supplier); and (3) future behavioral intention (intention to repeat purchase behavior). Our research has considered all of these three dimensions of loyalty to exam the consequences.

\section{Research Model and Hypothesis}

Huang and Hsieh [19] argued that there are four categories of antecedents: (1) the benefits and values a product or service may bring forth (its advantages); (2) the congruence with the existing usage (its compatibility); (3) the ease of use (its complexity); and (4) the user's domain expertise or related experiences. The first dimension contends that consumers' perceived advantages of using the existing or alternative service have an impact on the perception of losing existing benefit or incurred extra efforts associated with the switching process [27-30]. The second dimension maintains that the compatibility between current and alternative services is an important enabler of switching costs [16, 31]. The third dimension avers that complicated services associate with higher switching costs. Services that are easy to try and use engender less switching costs [9]. The fourth dimension postulates that consumers' service-related expertise determines their costs perception when switching to other providers [32]. Three of them (compatibility-related, complexity-related and advantagerelated) are concluded in our study. The single compatibility-related dimension is composed of inertia. We combine perceived ease of use and special treatment benefits into complexityrelated dimension. Advantage-related switching costs contain customization, quality of offering and interface quality.

Our proposed research model is presented in Figure 1. 


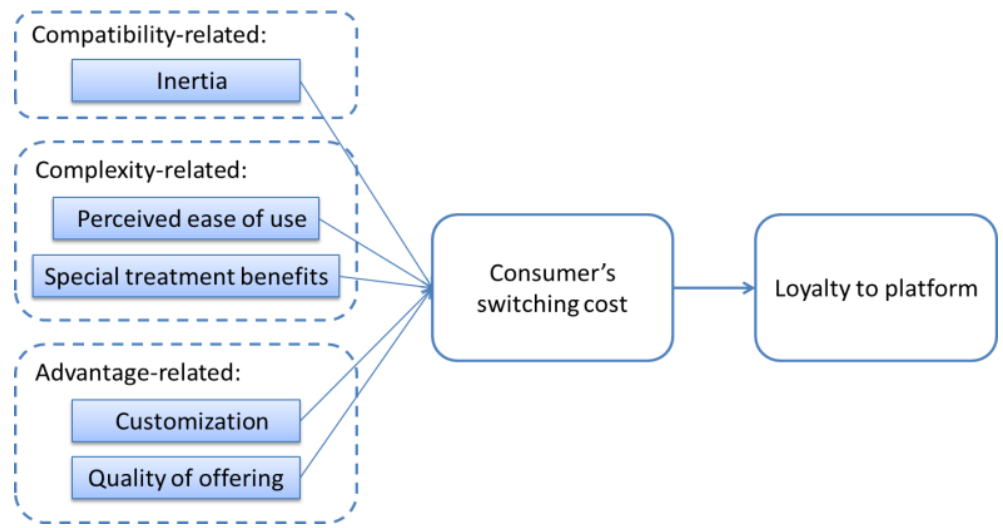

Figure 1. Research Model

\subsection{Inertia}

Individual level inertia receives scant attention in the Information System literature. In a general definition, inertia denotes remaining at rest or in uniform motion in the same straight line unless acted upon by some external force (Merriam-Webster Dictionary). In the context of business service, inertia with the current supplier is created when buyers search and compare alternatives: potential past investment or establish with new suppliers [29]. Actually, our behavior is influenced by inertia, also called persistence of habit(for example, various types of conditioned releasers or learned predispositions, which are not readily encompassed by attitude and intention) [33]. Triandis [34] interpreted inertia, a situation-behavior sequence, is or has become automatic, so that it occurs without self-instruction, and represents the link between a goal and actions that are instrumental in achieving this goal [35]. Put simply, past behavior is included as a substantive predictor of later behavior because repeated performance of behavior results in the establishment of habit [36]. Goal refers to end states or desired outcomes. Also, Ouellette and Wood [37] found that the direct effect of past behavior on future behavior is the most significant for the behaviors executed frequently and consistently in a stable context. That means prior experience is regarded as the determinant of behavior when testing, applying, or developing models of IS adoption and use. Inertia may be the most easily recognized when present alternatives are ignored or incentives fail. We should pay attention that the presence, knowledge of an alternative system, or incentives to using other systems, are not necessary requirements for the existence of inertia. Previous scholars conceptualized inertia as having behavioral, cognitive, and affective components and verified that inertia has effects on switching costs $[29,36]$. Based on prior research, we propose the following hypothesis:

Inertia of traditional ways is positively related to consumers' switching costs.

\subsection{Perceived Ease of Use}

In many studies of IS adoption, perceived ease of use has been a critical factor with the general perspective that perceived ease of use promotes service adoption [38]. In the context of e-commerce, ease of use refers to the extent to which a customer feels that the website is simple, intuitive, and user friendly [39]. A service that needs a large number of options or that includes lots of steps in its use will typically be seen as more complex. Accessibility of information and simplicity of the transaction processes are important antecedents to the successful completion of transactions. Enabling customers to search for information easily and making the information readily accessible and visible are the key to create a successful 
business [40]. People tend to use the platform to the extent they believe it will help them. But even if the platform is useful, they will give it up for it is too hard to use [41]. A number of factors render the service complex from a user's perspective. In some cases, information may be inaccessible because it is not in a logical place, or is buried too deeply [42]. Srinivasan et al. proposed that the more logical and ease of use, the less likely that customers make mistakes and the more likely that they will be satisfied [39]. In other cases, information may not be presented in a meaningful format, or even worse, needed or desired information may be entirely absent [42]. Some studies identified that switching costs can indeed be lower for services that are easier to use [43], but most researchers agree that ease of use is conductive to the formation of switching costs between customers and platform [9, 36, 39]. Hence, we establish the following hypothesis:

Perceived ease of use is positively related to consumers' switching costs.

\subsection{Special Treatment Benefits}

Special treatment gets at the notion that relational partners get special deals and treatment which is unavailable to non-relational customers [44]. Special treatment benefits combine the economic and customization advantages for the customer [45]. Economic benefits include monetary benefits (discount or price breaks for long-term customers) and non-monetary benefits (faster service or time saved in searching for another provider). Customization benefits include the customer's perceptions of preferential treatment, extra attention or personal recognition, and special services not available to other customers [46]. Special treatment benefits have an especially strong impact on customer to remain with service providers [44, 47-49]. As relational benefits develop in the context of those customers who have relationships with suppliers in face-to-face encounters [44], special treatment benefit is becoming an important impact on switching costs. And special treatment is more easily manipulated by platform than any other platforms (e.g., attractiveness of alternatives) [45]. Based on above arguments, we have the following hypothesis:

Special treatment is positively related to consumers' switching costs.

\subsection{Customization}

Simonson [50] supposed that customization means that the marketer provides the customer with the usual choice without waiting for the customer to ask for it, and that the customer accepts the offer in the context of these that customers, who seek no variety, purchase the same without considering other options [51]. Srinivasan [39] interpreted customization as the ability of the supplier to choose products, services, and the transactional environment for individual customers. In the current study, customization is operationally defined as the extent to which the platform can recognize a customer and tailor the choice of sellers with appropriate products or services and consumption experience of that customer.

There are multiple reasons why customization influences switching costs. Customization enhances the likelihood that customers will find something they are willing to get. Also it can signal high quality and lead to a better real match between customers and products [52]. Furthermore, customization creates perception of increased choice by enabling a quick focus on what the customer really want [53]. Finally, customers can complete their deal more efficiently when the platform is customized [39].

When the platform provides customization, which can't be offered via competitors, customers will be attracted and generate repurchase intentions, that is, customization has some effects on switching costs $[9,54]$. Thus, we hypothesize that:

Customization is positively related to consumers' switching costs. 


\subsection{Quality of Offering}

Consumer's evaluation of all positive value and benefits from an offering and the evaluation of the quality of services and products are regarded as quality of offering [55].

In mature industries, it is quality that distinguishes an organization from its rivals. As one of the few ways to offer differentiation and competitive advantage, quality of offering attracts new customers and contributes to the market share [56]. In addition, offering quality enhances customers' inclination to consume more and again, to consume other products and services, to reduce demand elasticity and to tell others their favorable experiences [57]. Quality perceptions are likely to be positively associated with customers' attitudes toward the organization and the likelihood of remaining a customer [58].

Burnham [15] stated a myopic belief that customer satisfaction and service quality are the only tools to manage customer retention. And prior studies have investigated the influence of quality of offerings on customer response $[13,59]$. Consumers perceive uncertainty about whether they would receive the same or higher level of quality after switching. Hence, perceived quality of offering is related to the perception of potential losses in the circumstances of switching and, therefore, to the perception of switching costs [56, 60]. Based on previous discuss, we establish the hypothesis:

Quality of offering is positively related to consumers' switching costs.

\subsection{Loyalty to Platform}

Understanding how or why a sense of loyalty develops in customers remains one of the crucial management issues at present [61]. IT is an important driver of customer loyalty. In the early days of e-commerce, it was believed that building customer loyalty was more difficult online than offline since a competing firm is "just a click away". But recent research has indicated that there is a significant evidence of customer loyalty within electronics markets [9]. Taking a behavioral intentions perspective of loyalty rather than a behavioral repurchase perspective avoids confusing spurious loyalty - loyalty of those who have a low relative attitude toward the organization but are constrained to repeated purchase -- with genuinely loyal customers [20].

Some scholars argued that the ability to generate switching costs and build customer loyalty is a major operator of success in the context of e-commerce [11]. The antecedents of loyalty concerned in research are mostly switching costs, quality and satisfaction. Switching costs always have a direct or indirect positive effect on customer loyalty [45, 62-64].

Previous studies have revealed a positive relationship between perceived switching costs and e-store loyalty and found that when consumers feel that the costs associated with changing from the original merchant are higher than those associated with creating a relationship with another merchant, they will tend to remain loyal to the original merchant $[65,66]$. For example, Kim [67] surveyed consumers of the Korean mobile telecommunication services and found that the switching costs have a direct impact on customer loyalty. And in a cross-cultural study, a large variance in behavioral intentions was explained by switching costs alone [47]. Compared to other factors (e.g., interface quality), switching costs are typical appropriate mediation factors in explaining users' e-loyalty in the context of $\mathrm{O} 2 \mathrm{O}$ [9]. Through customer lock-in effect, switching costs can prevent customers from defecting to another provider. Thus, we hypothesize:

Consumers' switching costs are positively related to consumers' loyalty to platform. 


\section{Research Design and Methodology}

\subsection{Measurement Development}

All measurement items were adapted from previous literatures with minor modifications in wording to make them relevant in the context of $\mathrm{O} 2 \mathrm{O}$ platforms. A seven-point Likert scale was used for all ratings. To enhance the validity of the proposed model's measurement items, a pilot study was performed with bachelor's degree students $(n=19)$ who were frequent taxihailing apps users in a MIS program to reduce possible ambiguity in the questions. Respondents were asked about any difficulty they may have encountered in the survey. Comments and suggestions on the item contents and structure of the instrument were solicited. Several revisions of questionnaire items were made.

\subsection{Survey Procedure}

This research takes China as the site of the empirical investigation because the supporting infrastructure required for taxi-hailing apps developments has been put in place. According to CNNIC's report, up to June, 2014, the number of net citizens in China has reached 591 million, and the number of mobile net citizens in China has reached 464 million. A Total of 298 questionnaires were distributed in the formal survey between April, 2014 and May, 2014. The questionnaires were distributed through paper-based questionnaire to people who were working in diverse industries and social institutions, including schools, universities, offices, and companies in China. Altogether, 263 questionnaires were collected. After reviewing, 35 questionnaires were eliminated due to invalid answers, leaving 228 questionnaires for the empirical analysis. Our sample comprised $46.1 \%$ male and $53.9 \%$ female respondents. The respondents are relatively young and generally well educated.

\section{Data Analysis and Results}

\subsection{Measurement Model Development}

Table 1. Construct Reliability and Convergent Validity

\begin{tabular}{llllll}
\hline Construct & Items & Loading & CR & AVE & Alpha \\
\hline Inertia & Int3 & 0.87 & 0.85 & 0.67 & 0.83 \\
& Int2 & 0.83 & & & \\
Ease of use & Int1 & 0.76 & & & \\
& Easy1 & 0.85 & 0.82 & 0.59 & 0.82 \\
& Easy2 & 0.82 & & & \\
& Easy4 & 0.79 & & & \\
Treatment & Easy3 & 0.74 & & & \\
benefit & Ben2 & 0.86 & 0.72 & 0.62 & 0.86 \\
& Ben1 & 0.81 & & & \\
Customization & Ben3 & 0.78 & & & \\
& Cust2 & 0.84 & 0.90 & 0.68 & 0.84 \\
& Cust4 & 0.81 & & & \\
Quality of offering & Cust3 & 0.78 & & & \\
& Cust1 & 0.71 & & & \\
& Off1 & 0.84 & 0.87 & 0.63 & 0.80 \\
& Off3 & 0.77 & & & \\
Switching cost & Off2 & 0.72 & & & \\
& Off4 & 0.69 & & & \multirow{2}{*}{0.81}
\end{tabular}




\begin{tabular}{llllll} 
& Cost1 & 0.84 & & & \\
Loyalty & Cost3 & 0.73 & & & \\
& Loy1 & 0.85 & 0.86 & 0.60 & 0.71 \\
& Loy3 & 0.83 & & & \\
\hline & Loy2 & 0.76 & & & \\
\hline
\end{tabular}

Both of validity and reliability were determined to evaluate the measurement model. Hair indicates that Cronbach's alpha value of 0.7 is the minimum acceptable value for reliability. The alpha value of each construct is over 0.7 , which represents good reliability. Content validity and construct validity are often used to measure validity. The variables in this study were derived from existing literature, thus exhibiting strong content validity. Construct validity was examined by investigating discriminant validity and convergent validity. The convergent validity of the scales was verified by using the criteria suggested by Fornell and Larcker [68]. All the factor loadings for all items exceed the acceptable level of 0.6, and all factor loadings are significantly related, via t-tests at $\mathrm{p}<0.001$, to their respective constructs, the composite reliability of the constructs ranged from 0.72 to 0.90 , and thus all exceeded the generally accepted value of 0.70 . In addition, the AVE ranged from 0.59 to 0.68 . Hence, all three conditions for convergent validity were met. Discriminant validity was examined using criteria suggested by Fornell and Larcker [68]. The shared variance between each pair of constructs was less than the average variances extracted, providing evidence of discriminant validity.

\subsection{Goodness Fit of Structural Godel}

To assess how well the model represents the data, this research employed AMOS 6.0 to evaluate "goodness of fit" indices. $\chi 2 / \mathrm{df}=1.58, \mathrm{RMSEA}=0.04$, GFI=0.88, AGFI=0.90, CFI $=0.92, \mathrm{NFI}=0.90$ and $\mathrm{IFI}=0.91$ are all within the commonly accepted thresholds suggested in the literature [68]. The fit indices indicate that the model provides a reasonably good fit.

Table 2. Goodness Fit Test

\begin{tabular}{llll}
\hline Fit index & Observed value & Recommendation value & References \\
\hline $\mathrm{X}^{2} / \mathrm{d} . f$ & 1.58 & Good fit $(\leq 3.0)$ & Fornell \& Larcker 1981 \\
GFI & 0.88 & Good fit $(\geq 0.80)$ & Hair et al. 1998 \\
AGFI & 0.90 & Good fit $(\geq 0.80)$ & Hair et al. 1998 \\
NFI & 0.90 & Good fit $(\geq 0.80)$ & Fornell \& Larcker 1981 \\
IFI & 0.91 & Good fit $(\geq 0.90)$ & Hair et al. 1998 \\
CFI & 0.92 & Good fit $(\geq 0.90)$ & Fornell \& Larcker 1981 \\
RMSEA & 0.04 & Good fit $(\leq 0.08)$ & Hair et al. 1998 \\
\hline
\end{tabular}

The result shows that inertia $(\beta=0.298, \mathrm{t}=3.542, \mathrm{p}<0.001)$ have positively effects on user's switching costs towards $\mathrm{O} 2 \mathrm{O}$ platform, which means consumers build higher switching costs because they get into the habit of using $\mathrm{O} 2 \mathrm{O}$ platform.

In the dimension of complexity-related antecedents, perceived ease of use $(\beta=0.314$, $\mathrm{t}=3.832, \mathrm{p}<0.001)$ shows a strong relationship with trust whereas special treatment $(\beta=0.187$, $\mathrm{t}=3.124, \mathrm{p}=0.563$ ) is not influential. The possible explanation for the result may be consumers prefer straightforward method to enjoy the service. However, when platform offers special treatment, there are always different criteria should be satisfied firstly which lead to consumer's give-up.

From the advantage-related perspective, customization $(\beta=0.276, \mathrm{t}=3.763, \mathrm{p}<0.001)$ and quality of offering $(\beta=0.331, t=4.106, p<0.001)$ have positive effects on consumer switching costs, which have been consistent with previous research. This result shows that consumers 
accept $\mathrm{O} 2 \mathrm{O}$ platform because they are understood by the platform. They are provided the most appropriate service and product. Needless to say, the product and service should be well enough. Otherwise, the customization is useless.

Finally, switching costs $(\beta=0.378, \mathrm{t}=4.672, \mathrm{p}<0.001)$ are confirmed to be positively related to e-loyalty as expected. Therefore, it is important to realize that there must be a prior development of e-loyalty before building a high switching cost.

\section{Discussion and Implications}

This research answers all proposed questions as what are set out in the introduction of this paper. A total of five hypotheses were statistically supported. The findings indicated that inertia, special treatment benefit, customization, and quality of offering were direct predictors of switching costs. Besides, switching costs were further found to be significantly related to customer's loyalty to $\mathrm{O} 2 \mathrm{O}$ platforms. Theoretical implications and practical implications are discussed as follows.

\subsection{Implications for Research}

The research provides a rich theoretical framework to explain the mechanism through which inertia influences customers' switching cost. Consumers form their habit because they think it meets their needs exactly and is worthy of being kept. The conceptual framework developed in this research can be used in understanding the impact of customer's current habits on platforms' switching costs in general.

And $\mathrm{O} 2 \mathrm{O}$ is of great importance in e-commerce. According to the data released by iResearch, the scale of local life service $\mathrm{O} 2 \mathrm{O}$ market has reached hundreds of billions in recent years. But less previous research discusses the topics of online to offline. Thus, our research takes one of the problems in $\mathrm{O} 2 \mathrm{O}$ as the goal to study.

The latest literature on switching costs focus on e-retailer. And the focus of our research to discuss and empirically test e-loyalty and explore the determinants of switching costs towards $\mathrm{O} 2 \mathrm{O}$ platform is among the first. And factors influencing switching costs mostly constitute a lock-in strategy to retain customers.

\subsection{Implications for Practice}

From a practical perspective, the findings will give insights and guidelines for both $\mathrm{O} 2 \mathrm{O}$ platform designers and service providers.

To platform designers, paying more attention to ease of use like the design of information mechanism may take effect. First, needed or desired information ought to be entirely intact. Second, information ought to be presented in a meaningful format. Third, information should be accessible and put in a logical place. Regarding the inertia of consumer, it would be difficult to control, but designers can affect it by adopting some strategies. For example, connecting with the offline merchants, who have the feedback mechanism to find out the factors, which have impact on developing customer's inertia via the characteristics of existing identified habit, would be a very useful tool to enhance the likelihood of forming user's inertia. Also they can affect inertia by improving and perfecting interface design such as information design, navigation design, visual design and etc. Once consumers get used to the existing interface, they will not change the style of interface easily.

Considering the customization, the service providers can design products and service which satisfy the needs of customers so that they can have an excellent experience. For people in different ages, they can get different services. For instance, the service providers can design the apps to automatically distinguish what kind of service the older need via their 
voice. Also the platform can develop their own recommended systems to enhance the efficiency of searching information they need. As for quality of offering, first, they should keep the good quality they offered. Second, to improve the quality, sellers can be guided to offer value-added service. A possible example is that a platform should not only provide the basic information about the offline merchant, but also offer contrastive information of the same service offered by different sellers so that customers can choose what they really need. They may as well improve their service quality through details. For instance, sending some blessing emails or messages at festivals is a clever strategy.

\section{Limitation and Suggestions}

The study has several inherent limitations due to the sample methods and measurement instruments used. These limitations indicate avenues for further studies.

First, the users of taxi-hailing apps are mostly the younger and from only several cities in China. Thus the sample can't stand for the whole users of $\mathrm{O} 2 \mathrm{O}$ platform, including the younger and older. Further studies should investigate different age groups of $\mathrm{O} 2 \mathrm{O}$ users.

Second, due to the variety of switching costs, the influence of antecedent can be neutralized. For example, the antecedent which hasn't been discussed in paper, breadth of use, can positively influence the switching cost of brand relationship loss but reduce the benefit loss costs because of supply-demand relationship. The more demand, the higher price. A comprehensive classification of switching costs should be considered in future research.

Third, we studied this research only from the perspective of customer. But the offline merchants are also the users of $\mathrm{O} 2 \mathrm{O}$ platform. And they are the major members that can't be neglected. Further studies can consider the antecedents of switching costs from these two perspectives. The antecedents may be absolutely different from the two angels. The combination of these two perspectives can make the analysis more complete and more efficient for platforms to retain both consumers and sellers with a better understanding of each other.

Finally, the amount of data collecting from taxi-hailing apps is limited due to limited resources and time. The small number of data may not well demonstrate our objective in this study. In addition, some potential factors influencing consumers' switching costs in $\mathrm{O} 2 \mathrm{O}$ platform may not be exposed. Therefore, it will not conductive to our further research. A longitudinal investigation would be more convincing in explaining how users' switching behaviors change over time.

\section{Acknowledgement}

This work has been supported by the Major Program of National Natural Science Foundation of China (No.91218301, No.71090402), the Fundamental Research Funds for the Central Universities (No.JBK120505), the National Natural Science Foundation of China (No.71302186, No.71371157, and No.71303191), and the Key Program of National Social Science Foundation of China (11AZD077).

\section{References}

[1] A. Rampell, "Why Online2Offline Commerce Is A Trillion Dollar Opportunity", Journal Issue, (2010).

[2] Z. Zhang, Z. Zhang, F. Wang, R. Law and D. Li, "Factors influencing the effectiveness of online group buying in the restaurant industry", International Journal of Hospitality Management, vol. 35, (2013). 
[3] M.-H. Hsu, C.-M. Chang, K.-K. Chu and Y.-J. Lee, "Determinants of repurchase intention in online group-buying: The perspectives of DeLone \& McLean IS success model and trust", Computers in Human Behavior, vol. 36, (2014).

[4] B. Staff, "O2O Commerce is the New Hot Methodology for Local Business", Journal Issue, (2010).

[5] J. Lim,"The Year of Online to Offline?", Journal. Issue, (2011).

[6] Y. Du and Y. Tang, "Study on the Development of O2O E-commerce Platform of China from the Perspective of Offline Service Quality", International Journal of Business and Social Science, vol. 4, no. 5 , (2014).

[7] C. Sun, "E-tailers fight to dominate online-to-offline market", Journal Issue, (2014).

[8] R. E. Anderson and S. S. Srinivasan, "E-Satisfaction and E-Loyalty: A Contingency Framework", Psychology \& Marketing, vol. 2, no. 20, (2003).

[9] H. H. Chang and S. W. Chen, "The impact of customer interface quality, satisfaction and switching costs on e-loyalty: Internet experience as a moderator", Computers in Human Behavior, vol. 24, (2008).

[10] S. Mouakket and M. A. Al-hawari, "Examining the antecedents of e-loyalty intention in an online reservation environment", Journal of High Technology Management Research, vol. 23, (2012).

[11] F. F. Reinchheld and P. Schefter, "E-loyalty: Your secret weapon on the web", Harvard Business Review, vol. 4, no. 78, (2000).

[12] M. E. Porter, "Competitive Strategy: Techniques for analyzing industries and competitors", New Your: Free Press, (1980).

[13] M. A. Jones, D. L. Mothersbaugh and T. A. Burnham, "Switching Barriers and Repurchase Intentions in Services", Journal of Retailing, vol. 2, no. 76, (2000).

[14] F. Claes, "A National Customer Satisfaction Barometer: The Swedish Experience", Journal of Marketing, vol. 1, no. 56, (1992).

[15] T. A. Burnham, J. K. Frels and V. Mahajan, "Consumer switching costs-a typology, antecedents, and consequences", Journal of the Academy of Marketing Science, vol. 2, no. 31, (2003).

[16] K. Paul, "Markets with consumer switching costs", Quarterly Journal of Economics, vol. 2, no. 102, (1987).

[17] K. C. Lee, N. Chung and S. Lee, "Exploring the influence of personal schema on trust transfer and swiching costs in brick-and-click bookstores", Information \& Management, vol. 48, (2011).

[18] C. Barroso and A. Picón, "Multi-dimensional analysis of perceived switching costs", Industrial Marketing Management, vol. 41, (2012).

[19] L.-Y. Huang and Y.-J. Hsieh, "Consumer electronics acceptance based on innovation attributes and switching costs: The case of e-book readers", Electronic Commerce Research and Applications, vol. 11, (2011).

[20] A. S. Dick and K. Basu, "Customer Loyalty: Toward an Integrated Conceptual Framework", Journal of the Academy of Marketing Science, vol. 2, no. 22, (1994).

[21] R. L. Oliver, Whence Consumer Loyalty?, Journal of Marketing. 4, 63, (1999)

[22] M. Uncles and G. Laurent, Editorial, International Journal of Research in Marketing, vol. 5, no. 14, (1997).

[23] K. E. Reynolds and S. E. Beatty, "Customer Benefits and Company Consequences of CustomerSalesperson Relationships in Retailing", Journal of Retailing, vol 1, no. 75, (1999).

[24] P. Hawkes, "Building brand loyalty and commitment", Journal of Brand Management, vol. 6, no. 1, (1994).

[25] S.-C. Chen, "The customer satisfaction-loyalty relation in an interactive e-service setting The mediators", Journal of Retailing and Consumer Services, vol. 19, (2012).

[26] B. Sharp and A. Sharp, "Loyalty programs and their impact on repeat-purchase loyalty patterns", International Journal of Research in Marketing, vol. 5, no. 14, (1997).

[27] S. G. Bharadwaj, P. R. Varadarajan and J. Fahy, "Sustainable competitive advantage in service industries: a conceptual model and research propositions", Journal of Marketing, vol. 57, (1993).

[28] S. M. Keaveney and M. Parthasarathy, "Customer switching behavior in online services: an exploratory study of the role of selected attitudinal, behavioral, and demographic factors", Journal of the Academy of Marketing Science, vol. 4, no. 29, (2001).

[29] A. H. Liu, "Customer value and switching cost in business services: developing exit barriers through strategic value management", The Journal of Business and Industrial Marketing, vol. 1, no. 21, (2006).

[30] C. Ranganathan, D. B. Seo and Y. Babad, "Switching behavior of mobile users: do users' relational investments and demographics matter?", European Journal of Information Systems Research, vol. 3, no. $15,(\mathbf{2 0 0 6})$. 
[31] J. W. Alba and J. W. Hutchinson, "Dimensions of consumer expertise", Journal of Consumer Research, vol. 13, (1987).

[32] C. W. Park, D. L. Mothersbaugh and L. Feick, "Consumer knowledge assessment", Journal of Consumer Research, vol. 21, (1994) June.

[33] A. H. Eagly and C. S., "The Psychology of Attitudes", Harcouri Brace Jovanovich College Publishers, (1993).

[34] H. C. Triandis, "Values, attitudes, and interpersonal behavior", Proceedings of Nebraska Symposium on Motivation, (1980).

[35] H. Aarts and A. Dijksterhuis, "Habits as Knowledge Structures: Automaticity in Goal-Directed Behavior", journal of Personality and Social Psychology, vol. 1, no. 78, (2000).

[36] H. Soongeun and L. Heeseok, "Antecedents of use-continuance in information systems: toward an integrative view", Journal of Computer Information Systems, vol. 48, (2008).

[37] J. A. Ouellette and W. Wood, "Habit and Intention in Everyday Life: The Multiple Processes by Which Past Behavior Predicts Future Behavior", Psychological Bulletin, vol. 1, no. 124, (1998).

[38] W. H. Delone and E. R. McLean, "Information Systems Success: The Quest for the Dependent Variable", Information Systems Research, vol. 1, no. 3, (1992).

[39] S. S. Srinivasan, R. Anderson and K. Ponnavolu, "Customer loyalty in e-commerce: an exploration of its antecedents and consequences", Journal of Retailing, vol. 1, no. 78, (2002).

[40] T. Sinioukov, "Mastering the web by the book", BookTech the Magazine, vol. 2, (1999).

[41] F. D. Davis, "Perceived Usefulness, Perceived Ease of Use, and User Acceptance of Information Technology", MIS Quarterly, vol. 3, no. 13, (1989).

[42] M. Cameron, "Content that works on the web, Target Marketing, (1999) November 1.

[43] P.-Y. Chen and L. M. Hitt, "Measuring switching costs and the determinants of customer retention in internet-enabled businesses: a study of the online brokerage industry", Information Systems Research, vol. 3, no. 13, (2002).

[44] H. J. R. Yen and K. P. Gwinner, "Internet retail customer loyalty: the mediating role of relational benefits", International Journal of Service Industry Management, vol. 5, no. 14, (2003).

[45] Y.-H. Chang and F.-Y. Chen, "Relational benefits, switching barriers and loyalty: A study of airline customers in Taiwan", Journal of Air Transport Management, vol. 13, (2007).

[46] K. P. Gwinner, D. D. Gremler and M. J. Bitner, "Relational benefits in services industries: the customer's perspective", Journal of the Academy of Marketing Science, vol. 26, (1998).

[47] P. G. Patterson and T. Smith, "A cross-cultural study of switching barriers and propensity to stay with service providers", Journal of Retailing, vol. 2, no. 79, (2003).

[48] L. Nagengast, H. Evanschitzky, M. Blut and T. Rudolph, "New Insights in the Moderating Effect of Switching Costs on the Satisfacion-Repurchase Behavior Link", Journal of Retailing, vol. 512, (2014).

[49] T. Hennig-Thurau, K. P. Gwinner and D. D. Gremler, "Understanding Relationship Marketing Outcomes: An Integration of Relational Benefits and Relationship Quality", Journal of Services Research, vol. 3, no. 4, (2002).

[50] I. Simonson, "Determinants of Customers' Responses to Customized Offers: Conceptual Framework and Research Propositions", Journal of Marketing, vol. 1, no. 69, (2005).

[51] J. R. Bettman, "An Information Processing Theory of Consumer Behavior", Journal of Consumer Research, vol. 25, (1979).

[52] A. Ostrom and D. Iacobucci, "Consumer tradeoffs and evaluation of services", Journal of Marketing, vol. 59, (1995).

[53] G. L. Shostak, "Breaking free from product marketing", Journal of Marketing, vol. 41, (1987).

[54] H.-T. Tsai and H.-C. Huang, "Determinants of e-repurchase intentions: An integrative model of quadruple retention drivers", Information \& Management, vol. 3, no. 44, (2007).

[55] D. Pick and M. Eisend, "Buyers' perceived switching costs and switching: a meta-analytic assessment of their antecedents", Journal of the Academy of Marketing Science, vol. 42, (2014).

[56] S. Aydin and G. Özer, "The analysis of antecedents of customer loyalty in the Turkish mobile telecommunications market", European Journal of Marketing, vol. 7/8, no. 39, (2005).

[57] K. A. Venetis and P. N. Ghauri, "The importance of service quality on customer retention: an empirical study of business service relationships", Proceedings of the Marketing in a Global Economy Conference, (2000).

[58] S. J. Bell, S. Auh and K. Smalley, "Customer relationship dynamics: service quality and customer loyalty in the context of varying levels of customer expertise and switching costs", Journal of the Academy of Marketing Science, vol. 2, no. 33, (2005). 
[59] S. E. Beatty, K. E. Reynolds, S. M. Noble and M. P. Harrison, "Understanding the Relationships Between Commitment and Voice: Hypotheses, Empirical Evidence, and Directions for Future Research", Journal of Services Research, vol. 3, no. 15, (2012).

[60] P.-F. CHOU and C.-S. LU, "Assessing Service Quality, Switching Costs and Customer Loyalty in Home-Delivery Services in Taiwan", Transport Reviews, vol. 6, no. 29, (2009).

[61] P. Luarn and H. H. Lin, "A customer loyalty model for e-service context", Journal of Electronic Commerce Research and Applications, vol. 4, no. 4, (2003).

[62] Y.-S. Wang, S.-C. Wu, H.-H. Lin and Y.-Y. Wang, "The relationship of service failure severity, service recovery justice and perceived switching costs with customer loyalty in the context of etailing", International Journal of Information Management, vol. 31, (2011).

[63] M. S. Janita and F. J. Miranda, "The antecedents of client loyalty in business-to-business (B2B) electronic marketplaces", Industrial Marketing Management, vol. 42, (2013).

[64] M. Blut, S. E. Beatty, H. Evanschitzky and C. Brock, "The Impact of Service Characteristics on the Switching Costs-Customer", Journal of Retailing, vol. 4, (2014).

[65] G. Balabanis, N. Reynolds and A. Simintiras, "Bases of e-store loyalty: Perceived switching barriers and satisfaction", Journal of Business Research, vol. 59, (2006).

[66] M. Colgate and B. Lang, "Switching barriers in consumer markets: An investigation of the financial services industry", Journal of Consumer Marketing, vol. 4, no. 18, (2001).

[67] M. K. Kim, M. C. Park and D. H. Jeong, "The effects of customer satisfaction and switching barrier on customer loyalty in Korean mobile telecommunication services", Telecommunications Policy, vol. 28, (2004).

[68] F. Claes and D. F. Larcker, "Measurement Error", Journal of Marketing Research, vol. 1, no. 18, (1981).

\section{[69] Authors}

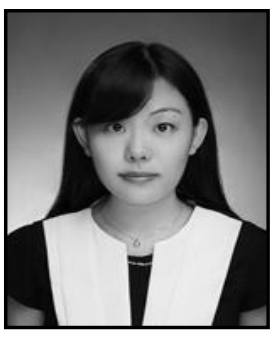

Minghui Kang, (kmhui66@126.com) is an Assistant Professor of Finance at the Southwest Jiaotong University. She received her Ph.D.in Finance from Chungnam National University, South Korea. Her main research interests include corporate finance, investment, derivatives, risk management. She has published in scholarly journals and international conferences including the Behaviour \& Information Technology, International Business Review, Pacific Asia Conference on Information Systems, etc.

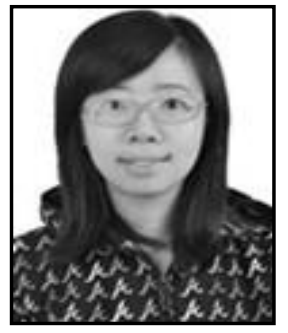

Yiwen Gao, (a419360294@qq.com) is an undergraduate student of the info management and info system (Business intelligence) department at the Southwestern University of Finance and Economics. Her main research interest is user behavior in different internet contexts. She has published in international conferences, including the Pacific Asia Conference on Information Systems and International Conference of Management on e-Commerce and e-Government.

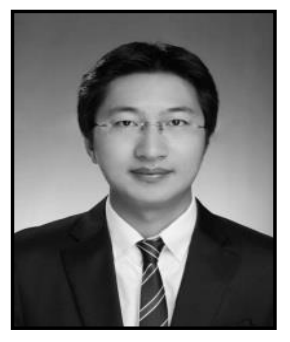

Tao Wang, (ccnuwt@swufe.edu.cn) is an Associate Professor of Management Information Systems at the Southwestern University of Finance and Economics. He received his Ph.D.in MIS from Chungnam National University, South Korea. His main research interests include information system acceptance and user behavior, electronic payment security and model, web 2.0 and enterprise 2.0 applications. He has published in scholarly journals and international conferences including the Behaviour \& Information Technology, Electronic Commerce Research and Applications, Journal of Information Technology 
Applications and Management, Pacific Asia Conference on Information Systems, etc.

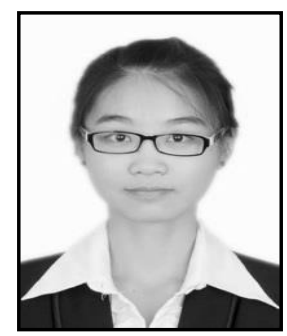

Meng Wang (18010612066@163.com) is an undergraduate student in the info management and info system (Financial intelligence) department at the Southwestern University of Finance and Economics. Her main research interests include user behavior and trust model in the internet financial environment. She has published in the PACIS (Pacific Asia Conference on Information Systems). 